\title{
Descripción de sistemas productivos en hatos lecheros del Valle del Mantaro y factores de riesgo para la Diarrea Viral Bovina y Neosporosis
}

\author{
Description of production systems in dairy cattle herds in the Mantaro \\ Valley, and risk factors associated with Bovine Viral Diarrhea and \\ Neosporosis
}

\author{
Fernando Arauco Villar ${ }^{1}$ \\ Universidad Nacional del Centro del Perú \\ faraucov@gmail.com
}

\section{RESUMEN}

Se realizó un estudio epidemiológico para describir los sistemas de producción de 37 hatos bovinos lecheros (425 vacas en producción) en cuatro provincias del Valle del Mantaro, región Junín, Perú, e identificar los factores de riesgo involucrados en la presencia de Diarrea Viral Bovina (DVB) y Neosporosis, mediante una encuesta epizootiológica y la prueba inmunodiagnóstica ELISA. Los sistemas de producción prevalentes son de tipo semi intensivo, abiertos o semi abiertos, de tipo mixto, 3 perros/establo, con componentes poco adecuados o inadecuados (instalaciones, uso de registros, manejo sanitario y reproductivo, de personal, sistemas de higiene y limpieza, manejo reproductivo); 64,8 \% con uno a más de tres vacas repetidoras. El riesgo epidemiológico endógeno (alto y moderado) está presente en las cuatro provincias asociado al mayor número de casos de DVB y Neosporosis siendo menos trascendente los factores de tipo exógeno. Son factores de riesgo para DVB el sistema de producción de tipo intensivo (OR: 6,545), el uso de inseminación artificial (OR: 7,895), la presencia de ratas (OR: 5,714), y asociación positiva entre las prevalencias de DVB con vacas repetidoras y casos de abortos y nacimientos anómalos. Son factores de riesgo para Neosporosis la presencia de ratas (OR: 18,417), manejo sanitario inadecuado (OR: 7,5 ) y manejo inadecuado del personal (OR: 12,75), comportándose como factor de protección la crianza mixta con otras especies domésticas (OR: 0,298).

\begin{abstract}
An epidemiological study was carried out to describe the dairy cattle production systems in 37 dairy cattle herds (425 productive cows) in four Mantaro Valley provinces in Junin region, Peru. To identify the risk factors involved on (Bovine Viral Diarrhea) DVB and Neosporosis, an epizootiological survey and ELISA diagnostic testing were performed. Dairy cattle production systems prevalent are semi-intensive, open or half-open, mixed type, 3 dogs/stable, which have little appropriate components (cattle facilities, registries use, health management, staff, hygiene and cleaning systems, reproductive management); $64,8 \%$ have one to three repeat breeders. The endogenous epidemiological risk (high and moderate) is present in four provinces associated with the greater number of DVB and Neosporosis cases, being less transcendent the exogenous factors. DVB risk factors are: intensive production system (OR: 6,545), artificial insemination (OR: 7,895), rats presence (OR: 5,714), and positive association between DVB prevalences with repeat breeders and abnormal births and abortions risk. Neosporosis risk factors are: rats presence (OR: 18,417), inappropriate health management (OR: $7,5)$ and improper staff handling (OR: 12,75), as a protection factor the mixed breeding with other domestic species (OR: 0,298).
\end{abstract}

Keywords: Bovine Viral Diarrhea, neosporosis, production system, risk factors, odds ratio.

Palabras clave: Diarrea viral bovina, neosporosis, sistema de producción ganaderos, valle del mantaro, factores de riesgo.

Historial del artículo:

Recibido: 16 de julio de 2015. Aprobado: 13 de septiembre de 2015. Disponible en línea: 30 de diciembre de 2015

1 Médico Veterinario; Mag en ; Profesor Principal del departamento académico de Ciencia Animal y Gestión Ambiental de la Facultad de Zootecnia de la Universidad Nacional del Centro del Perú. 


\section{INTRODUCCIÓN}

El análisis de los componentes principales de los sistemas productivos ganaderos permite la identificación de aquellas variables que influyen en la productividad del hato así como en la presentación de determinadas enfermedades. La variedad de condiciones climáticas y las características de los sistemas productivos (manejo, alimentación, reproducción, etc.) generan heterogeneidad en la productividad de los hatos, donde el componente reproductivo suele ser una consecuencia de las mismas (1).

Existe la necesidad de tomar conocimiento de los sistemas de producción prevalentes en el Valle del Mantaro para poder disponer de cierta información que nos permita discriminar sus componentes y variables, los mismos que pueden ser determinantes en la presentación de enfermedades que afecten la productividad y la eficiencia reproductiva del ganado.

En el Valle del Mantaro se evaluó la prevalencia de DVB en muestras de leche encontrando una seroprevalencia muestral de $72,4 \%$ (2) y el virus fue detectado en todos los hatos muestreados; también se encontró una prevalencia del $73 \%$ para VDVB (virus Diarrea Viral Bovina) en muestras de leche en tanque de hatos del Valle del Mantaro (3). En vacas Brown Swiss de la SAIS Pachacútec, se reportó la presencia de anticuerpos contra $N$. caninum en $12,8 \%$ (4) y en vacas lecheras de la margen izquierda del Valle del Mantaro, Concepción, se encontró una frecuencia de anticuerpos contra $N$. caninum de $46,7 \%$ y todos los establos, menos uno, presentaron al menos un animal positivo a N. caninum (5).

El problema de investigación planteado se relaciona con el desconocimiento de los componentes de manejo, nutricional reproductivo y sanitario de los sistemas de producción practicados en los hatos bovinos lecheros del Valle del Mantaro y que pueden constituirse como factores (endógenos y exógenos) potenciales de riesgo para contraer enfermedades que afecten su eficiencia reproductiva y por consiguiente, su productividad, para lo cual se trazaron como objetivos describir y cuantificar los principales componentes de los sistemas de producción de hatos bovinos lecheros del Valle del Mantaro y evaluarlos como factores de riesgo para el desarrollo de enfermedades que afecten sobre todo la reproducción, como la DVB y la Neosporosis.

La hipótesis es que los componentes de los sistemas de producción relacionados al manejo del ganado son factores importantes para el desarrollo de enfermedades en la etapa reproductiva. El reconocimiento de estos factores permitirá diseñar medidas para su control, biocontención y prevención convenientes para la ganadería lechera del Valle del Mantaro, permitiendo que el laboratorio de Sanidad
Animal de la Facultad de Zootecnia de la Universidad Nacional del Centro del Perú (UNCP) pueda trabajar coordinadamente con la autoridad sanitaria y los productores en el monitoreo de estas patologías.

\section{MATERIAL Y MÉTODOS}

En el estudio participaron establos de bovinos lecheros del Valle del Mantaro, Región Junín, márgenes izquierda y derecha, con diversos pisos altitudinales, en las provincias de Huancayo, Chupaca, Concepción y Jauja y sus zonas de influencia. La altitud oscila de 3 150 a 3500 m s.n.m., y ubicado geográficamente a $11^{\circ} 55^{\prime}$ de latitud sur y $75^{\circ} 18$ de longitud oeste.

El diseño de la investigación fue descriptivo correlacional y transversal, para lo cual se seleccionaron aleatoriamente 37 hatos (Huancayo 9 hatos, Concepción 11, Jauja 9 y Chupaca 8).

Para calcular el tamaño de la muestra se consideraron las prevalencias referenciales de DVB y Neosporosis reportadas para la región Junín y el Valle del Mantaro, y se empleó la ecuación siguiente (6):

$$
n=(Z \alpha / 2)^{2} \frac{\mathrm{pq}}{L^{2}}
$$

El tamaño muestral fue de 425 animales, y el número de animales/provincia fue proporcional al tamaño poblacional de vacas de las cuatro provincias (7), obteniéndose 145, 33, 125 y 122 vacas para Huancayo, Chupaca, Concepción y Jauja, respectivamente.

Las muestras de sangre se obtuvieron por punción directa de la arteria coccígea media y fueron depositadas en viales de $2 \mathrm{ml}$ y conservados en congelación a $-20{ }^{\circ} \mathrm{C}$ hasta su procesamiento para detectar anticuerpos contra VDVB y anti $N$. caninum, usando los kits comerciales: CIVTEST Bovis BVD/BD P80, CIVTEST Bovis Neospora (Lab. Hipra) e IDEXX BVDV Total Ab y c ELISA VMRD 280-5 (Lab. Multivet).

Los laboratorios que participaron fueron la Unidad de Biología y Genética Molecular de la Facultad de Medicina Veterinaria de la Universidad Nacional Mayor de San Marcos (UNMSM) y el de Sanidad Animal de la Facultad de Zootecnia de la UNCP.

La encuesta epizootiológica fue aplicada a los responsables de la explotación (propietarios o administradores) para obtener información sobre las variables evaluadas, complementándose con la revisión de los registros existentes. La encuesta, previamente, fue sometida a una validación de su contenido utilizando el criterio de expertos por el método Delphi y la prueba no paramétrica de 
Kendall (8). Se explicó a los encuestados los alcances del estudio, firmando la Ficha de Consentimiento Informado, en concordancia con las consideraciones bioéticas del proyecto de investigación.

Se utilizó el paquete estadístico SPSS v21, para determinar las frecuencias y porcentajes de diferentes variables, gráficos de asociación de variables y análisis de regresión logística binaria, tablas de contingencia con chi-cuadrado para el contraste de independencia y las medidas de asociación y riesgo como el Odds Ratio (OR).

\section{RESULTADOS}

No hubo diferencias en el número de hatos muestreados por provincia (DE: 1,26 y CV: $14 \%$ ). En la tabla 1 se reportan las variables evaluadas por de las vacas tenían entre 1 y 5 años de edad, y el predominio de vacas jóvenes guarda relación con el número de lactancias, pues $70,4 \%$ de las vacas tenían de 1 a 3 lactaciones (partos). La mayoría de hatos fueron de tipo abierto $(45,9 \%$ ) y semi abiertos $(21,7 \%)$. El reemplazo de vacas sólo con terneras criadas en el mismo hato se dio en $43,2 \%$ de hatos; mientras, $56,8 \%$ adquieren sus reemplazos de otros hatos o provienen de su mismo hato, indistintamente, sin un plan de crianza establecido para este aspecto. El 13,5\% de los productores entregan exclusivamente su producto a la empresa acopiadora Gloria S.A., 27 $\%$ lo hace a otros acopiadores formales o informales ("porongueo"), 18,9\% de productores destina la leche para autoconsumo y auto insumo (elaboración de productos lácteos) y $40,6 \%$ utiliza dos o más opciones para el destino de su producción, de acuerdo a la ley de oferta y demanda, así como a ciertas circunstancias medioambientales.

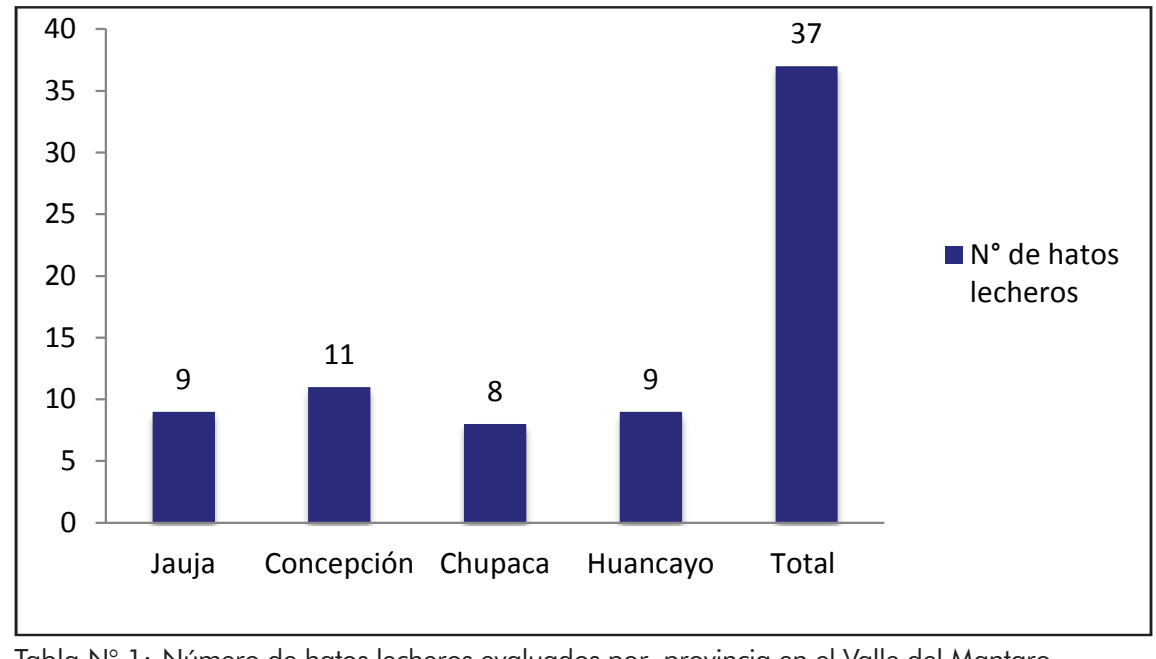

Tabla $\mathrm{N}^{\circ}$ 1: Número de hatos lecheros evaluados por provincia en el Valle del Mantaro.

categorías y consignadas en la encuesta referidas a los diversos factores, tanto endógenos o exógenos a los hatos evaluados.

El promedio y la desviación estándar del número de servicios de IA/preñez fue 2,14 0,47 (mínimo: 1,5 y máximo: 3,0 ) para vacas clínicamente sanas, es decir sin problema reproductivo evidente; $40 \%$ de los productores declaró necesitar dos servicios/preñez (tabla 2).

Los hatos evaluados mayormente usan sistemas productivos de tipo semi intensivo $(62,2 \%)$ e intensivo $(35,1 \%)$; el $37,8 \%$ se dedica exclusivamente a la cría de ganado bovino lechero, y el 62,2 \% además cría otras especies domésticas (principalmente ovinos). La mayor parte de las vacas muestreadas fueron de raza Brown Swiss, seguido por Holstein y en menor cantidad fue ganado cruzado y criollo. El $64,4 \%$
El 27,1 \% de los establos encuestados poseen instalaciones que reúnen las condiciones adecuadas mínimas para un buen manejo y salud del hato pero $72,9 \%$ son poco adecuadas o inadecuadas, asimismo en el $89,2 \%$ de los establos las prácticas de higiene de las instalaciones son poco adecuadas o inadecuadas.

El $56,8 \%$ de los establos están localizados en las inmediaciones o en los mismos centros poblados. Asimismo el 29,7 \% utiliza agua potable de la red pública como fuente de agua de bebida para sus animales, y los hatos más alejados de las zonas urbanas utilizan puquiales, acequias de regadío; la mayoría (51,4 \% de los hatos) emplea dos o más fuentes de agua.

El $100 \%$ de los productores encuestados reportó presencia de ratas en sus establecimientos, de manera ocasional o permanente; 51,4\% reportó la presencia 
Tabla $\mathrm{N}^{\circ}$ 1: Variables categorizadas y evaluadas.

\begin{tabular}{|c|c|c|c|}
\hline Variable & Categoría & $\mathbf{N}^{\circ}$ & $\%$ \\
\hline \multirow[t]{3}{*}{ Sistema de Producción } & Semi intensivo & 23 & 62,2 \\
\hline & Intensivo & 13 & 35,1 \\
\hline & Extensivo & 1 & 2,7 \\
\hline \multirow[t]{4}{*}{ Tamaño del hato (número de vacas) } & $11-30$ & 16 & 43,3 \\
\hline & Más de 60 & 10 & 27,0 \\
\hline & $1-10$ & 6 & 16,2 \\
\hline & $31-60$ & 5 & 13,5 \\
\hline \multirow[t]{5}{*}{ Razas y tipos raciales de bovinos } & Brown Swiss & 189 & 44,4 \\
\hline & Holstein & 115 & 27,1 \\
\hline & Cruzado & 90 & 21,2 \\
\hline & Criollo & 30 & 7,1 \\
\hline & Otra raza & 1 & 0,2 \\
\hline \multirow{4}{*}{$\begin{array}{l}\text { Edad (años) por rangos de las vacas } \\
\text { evaluadas }\end{array}$} & $>3-5$ & 148 & 34,8 \\
\hline & $>1-3$ & 126 & 29,6 \\
\hline & $>5-7$ & 85 & 20,0 \\
\hline & $>7$ & 66 & 15,5 \\
\hline \multirow{4}{*}{$\begin{array}{l}\text { Número de lactancias (partos) de las } \\
\text { vacas evaluadas }\end{array}$} & $1-3$ & 299 & 70,4 \\
\hline & $>3-5$ & 82 & 19,3 \\
\hline & $>5-7$ & 35 & 8,2 \\
\hline & $>7$ & 9 & 2,1 \\
\hline \multirow[t]{3}{*}{ Tipo de hato } & Abierto & 17 & 45,9 \\
\hline & Cerrado & 12 & 32,4 \\
\hline & Semi abierto & 8 & 21,7 \\
\hline \multirow[t]{3}{*}{ Origen de los reemplazos } & De otro hato & 1 & 2,7 \\
\hline & Propio & 16 & 43,2 \\
\hline & Ambos & 20 & 54,1 \\
\hline \multirow[t]{2}{*}{ Tipo de crianza } & Solo bovinos & 14 & 37,8 \\
\hline & Mixta (bovinos y otras especies) & 23 & 62,2 \\
\hline \multirow[t]{3}{*}{ Crianza de otras especies } & Ovinos & 15 & 65,2 \\
\hline & Más de dos especies & 7 & 30,4 \\
\hline & Camélidos & 1 & 4,3 \\
\hline \multirow[t]{2}{*}{ Colindancia con centro poblado } & $\mathrm{Si}$ & 21 & 56,8 \\
\hline & No & 16 & 43,2 \\
\hline \multirow[t]{2}{*}{ Presencia de animales silvestres } & Varias especies (incluyendo ratas) & 19 & 51,4 \\
\hline & Solo ratas & 18 & 48,6 \\
\hline Suministro de alimentación & Si & 19 & 51,4 \\
\hline \multirow[t]{2}{*}{ complementaria y suplementaria } & No & 10 & 27,0 \\
\hline & Ocasionalmente & 8 & 21,6 \\
\hline \multirow[t]{4}{*}{ Fuente de agua de bebida } & Más de dos fuentes & 19 & 51,4 \\
\hline & Potable de red pública & 11 & 29,7 \\
\hline & Puquio & 6 & 16,2 \\
\hline & Acequia & 1 & 2,7 \\
\hline \multirow[t]{2}{*}{ Tipo de ordeño } & Manual & 19 & 51,4 \\
\hline & Mecánico & 18 & 48,6 \\
\hline
\end{tabular}




\begin{tabular}{|c|c|c|c|}
\hline Variable & Categoría & $\mathrm{N}^{\circ}$ & $\%$ \\
\hline \multirow[t]{2}{*}{ Frecuencia de ordeños/día } & 2 & 34 & 91,9 \\
\hline & 1 & 3 & 8,1 \\
\hline \multirow[t]{5}{*}{ Destino de la producción láctea } & Dos o más opciones & 15 & 40,6 \\
\hline & Porongueo & 10 & 27,0 \\
\hline & Empresa Gloria & 5 & 13,5 \\
\hline & Autoinsumo & 4 & 10,8 \\
\hline & Autoconsumo & 3 & 8,1 \\
\hline \multirow[t]{3}{*}{ Tipo de reproducción } & Inseminación artificial (IA) & 18 & 48,7 \\
\hline & Ambos (IA/MN) & 11 & 29,7 \\
\hline & Monta natural (MN) & 8 & 21,6 \\
\hline Tipo de semen empleado en la & Importado y nacional & 12 & 41,4 \\
\hline \multirow[t]{2}{*}{ Inseminación Artificial ( IA) } & Nacional & 10 & 34,4 \\
\hline & Importado & 7 & 24,2 \\
\hline \multirow{4}{*}{$\begin{array}{l}\text { Uso de registros de ganadería (de } \\
\text { producción, reproducción y sanidad) }\end{array}$} & No lleva ningún tipo de registros & 17 & 45,9 \\
\hline & De producción y reproducción & 14 & 37,8 \\
\hline & Lleva todos los registros & 5 & 13,6 \\
\hline & Solo registros productivos & 1 & 2,7 \\
\hline \multirow{3}{*}{$\begin{array}{l}\text { Procedimientos de eliminación de restos } \\
\text { placentarios }\end{array}$} & Malo & 26 & 70,3 \\
\hline & Bueno & 10 & 27,0 \\
\hline & Excelente & 1 & 2,7 \\
\hline \multirow[t]{3}{*}{ Tipo de instalaciones } & Inadecuado & 14 & 37,8 \\
\hline & Poco adecuado & 13 & 35,1 \\
\hline & Adecuado & 10 & 27,1 \\
\hline \multirow[t]{3}{*}{ Higiene de instalaciones } & Inadecuado & 18 & 48,6 \\
\hline & Poco adecuado & 15 & 40,6 \\
\hline & Adecuado & 4 & 10,8 \\
\hline \multirow[t]{3}{*}{ Manejo sanitario del hato } & Inadecuado & 18 & 48,6 \\
\hline & Poco adecuado & 13 & 35,2 \\
\hline & Adecuado & 6 & 16,2 \\
\hline \multirow[t]{3}{*}{ Manejo del personal de ganadería } & Poco adecuado & 19 & 51,4 \\
\hline & Inadecuado & 16 & 43,2 \\
\hline & Adecuado & 2 & 5,4 \\
\hline \multirow{4}{*}{$\begin{array}{l}\text { Casos de retención de placenta y } \\
\text { metritis/último año }\end{array}$} & De $1-3$ & 16 & 43,3 \\
\hline & No hay casos reportados & 12 & 32,4 \\
\hline & $>3$ & 9 & 24,3 \\
\hline & Abortos & 15 & 405 \\
\hline \multirow{3}{*}{$\begin{array}{l}\text { Abortos y nacimientos anómalos/último } \\
\text { año }\end{array}$} & Abortos y nacimientos anómalos & 12 & 32,5 \\
\hline & No hubo casos reportados & 8 & 21,6 \\
\hline & Nacimientos anómalos & 2 & 5,4 \\
\hline Presencia de vacas repetidoras/último & $1-3$ & 13 & 52,0 \\
\hline \multirow{2}{*}{ año } & $>3$ & 11 & 44,0 \\
\hline & No hay casos & 1 & 4,0 \\
\hline \multirow[t]{4}{*}{ Causales de saca del ganado } & Edad & 16 & 43,2 \\
\hline & Dos o más causas & 16 & 43,2 \\
\hline & Problemas reproductivos & 3 & 8,1 \\
\hline & Baja producción & 2 & 5,5 \\
\hline
\end{tabular}


ocasional, además de estos roedores, de otras especies de animales silvestres dentro del predio (aves silvestres, venados, zorros, etc.).

Un porcentaje importante de productores $(48,6 \%)$ utiliza el ordeño mecánico aunque $51,4 \%$ utiliza todavía el ordeño manual, muchos de ellos con ternero al pie, y la mayoría $(91,9 \%)$ realiza dos ordeños al día (2X).

En el $73 \%$ de hatos se suministra alimentación complementaria/suplementaria (concentrado, sales minerales, ensilado/heno) al ganado, algunos de manera sistemática como parte de su manejo, pero en su mayoría de manera ocasional dependiendo de su disponibilidad y asequibilidad, sobre todo en períodos de estiaje donde suele escasear el forraje; un $27 \%$ de los productores declaró que solo alimentaban a sus vacas en producción con pastoreo, y esto se aprecia en pequeños productores y los ubicados en zonas más altas.

Tabla $N^{\circ}$ 2: Número de servicios/preñez.

\begin{tabular}{ccr}
\hline $\mathrm{N}^{\circ}$ servicios/preñez & Frecuencia & $\%$ \\
\hline 1,5 & 2 & 8,0 \\
1,6 & 1 & 4,0 \\
1,8 & 4 & 16,0 \\
2,0 & 10 & 40,0 \\
2,1 & 1 & 4,0 \\
2,5 & 2 & 8,0 \\
2,6 & 1 & 4,0 \\
3,0 & 4 & 16,0 \\
Total & 25 & 100,0 \\
\hline
\end{tabular}

El $48,7 \%$ utiliza de manera exclusiva y sistemática la inseminación artificial (con semen nacional o importado) y $29,7 \%$ usa tanto la monta natural (MN) o la inseminación artificial (IA), de acuerdo a la disponibilidad y asequibilidad del semen, del tipo de ganado (vacas mejoradas o no) o si se desea asegurar la preñez en algunos casos. La MN de manera exclusiva se emplea en el $21,6 \%$ de los hatos (con crianza semi intensiva y extensiva). Por lo general no se sigue un plan de mejoramiento genético establecido a priori para cada establecimiento, y se adquiere el semen por conveniencia económica o por la disponibilidad existente. De los 29 productores que emplean la IA de manera exclusiva $u$ ocasional, 24,2 \% utiliza solo semen importado y 41,4\% indistintamente semen importado o nacional.

En 16,2 \% de los hatos evaluados se realiza un adecuado manejo sanitario mientras que en $35,2 \%$ éstas son poco adecuadas, y en $48,6 \%$ inadecuadas. En el $45,9 \%$ de los hatos encuestados no se lleva ningún tipo de registro y solo un 13,6 \% tiene implementados sus registros de manera adecuada (registros de producción, registros reproductivos y registros sanitarios de los animales); un 40,5\% lleva solo un tipo de registros y de manera incompleta. Solo en $5,4 \%$ de los hatos encuestados se realiza un adecuado manejo del personal y 43,2 \% lo hace de manera inadecuada.

El $86,4 \%$ de los productores encuestados reportan específicamente a la edad y a dos o más factores simultáneos (edad, problemas reproductivos o bajos niveles de producción) como causales de saca del ganado.

El promedio del número de servicios de IA/preñez fue 2.14 (D.E. 0.4655; mínimo: 1.5 y máximo: 3.0), para vacas clínicamente sanas, sin problema reproductivo evidente; $40 \%$ de los productores declaró necesitar dos servicios/preñez (moda).

El número promedio de perros en los predios encuestados es de tres/establo (D.E. 1.943), con un

Tabla №3: Número de perros/establo.

\begin{tabular}{ccc}
\hline$N^{\circ}$ perros/establo & Frecuencia & $\%$ \\
\hline 0 & 1 & 2,7 \\
1 & 5 & 13,5 \\
2 & 12 & 32,4 \\
3 & 8 & 21,6 \\
4 & 4 & 10,8 \\
5 & 3 & 8,1 \\
6 & 2 & 5,5 \\
8 & 1 & 2,7 \\
9 & 1 & 2,7 \\
Total & 37 & 100,0 \\
\hline
\end{tabular}

máximo de nueve y un mínimo de cero. En el 32,4 \% de los hatos encuestados se encontró la presencia de dos perros (moda).

En el 64,8 \% de hatos evaluados se reportó de una a más de tres casos de vacas repetidoras en el último año. Casi dos terceras partes de los hatos encuestados $(67,6 \%)$ reportaron haber tenido entre uno hasta más de tres casos de retención placentaria y/o metritis, mientras que un $32,4 \%$ no reportó estos casos en el último año. 78,4 \% de hatos declararon haber tenido casos de abortos o nacimientos anómalos (natimortos, terneros con malformaciones congénitas o débiles) o ambos casos durante el último año.

Considerando los resultados globales de la encuesta epizootiológica aplicada a los 37 hatos encuestados y tomando en consideración los criterios para categorizar los diversos factores intervinientes como endógenos o exógenos, se ha asociado el tipo de riesgo epidemiológico para la potencial presentación de enfermedades en el hato (DVB y Neosporosis) con 
las provincias (Huancayo, Chupaca, Concepción y Jauja).

La provincia de Jauja presenta de manera exclusiva un nivel de riesgo epidemiológico endógeno alto más que para el resto de provincias; el nivel de riesgo moderado es mayor para Huancayo y en menor grado en Concepción y Chupaca. Se ha reportado un solo hato con nivel de riesgo epidemiológico endógeno bajo (en la provincia de Huancayo). Considerando de los hatos evaluados existe un riesgo epidemiológico alto por causas endógenas para la presentación de enfermedades como DVB y Neosporosis.

Para el caso del riesgo epidemiológico exógeno, los niveles moderado y bajo de este tipo de riesgo se asocian en mayor grado en las cuatro provincias, mientras que el riesgo epidemiológico exógeno alto se asocia en menor grado con Huancayo, Concepción y Jauja (no se detectó este tipo de riesgo para la provincia

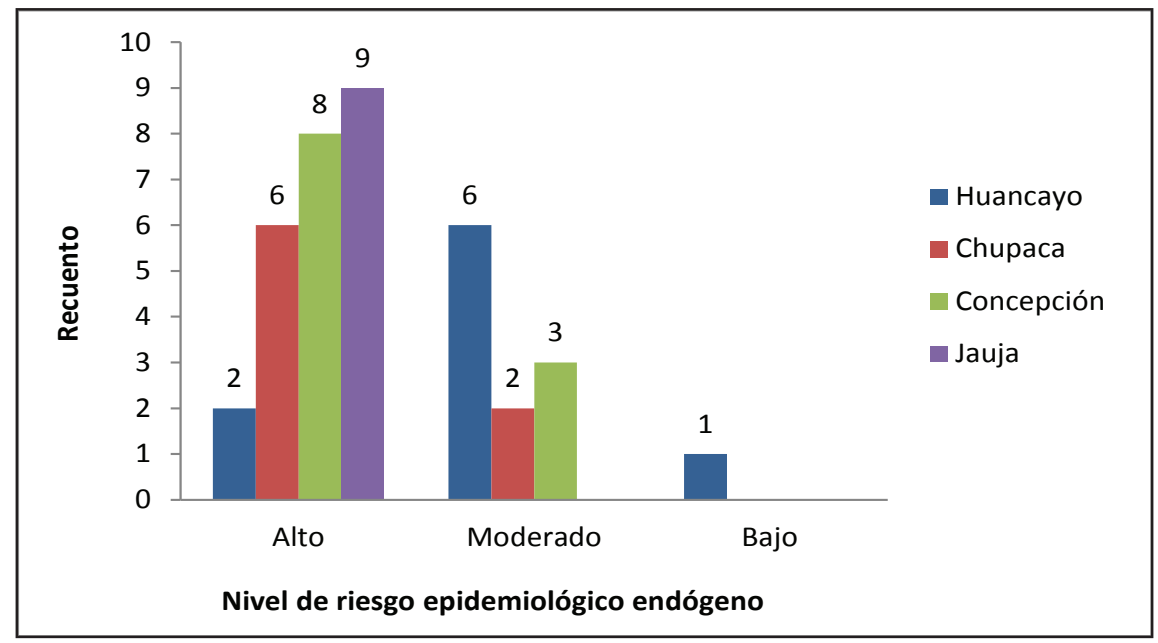

Figura $\mathrm{N}^{\circ}$ 2: Niveles de riesgo endógeno/provincia.

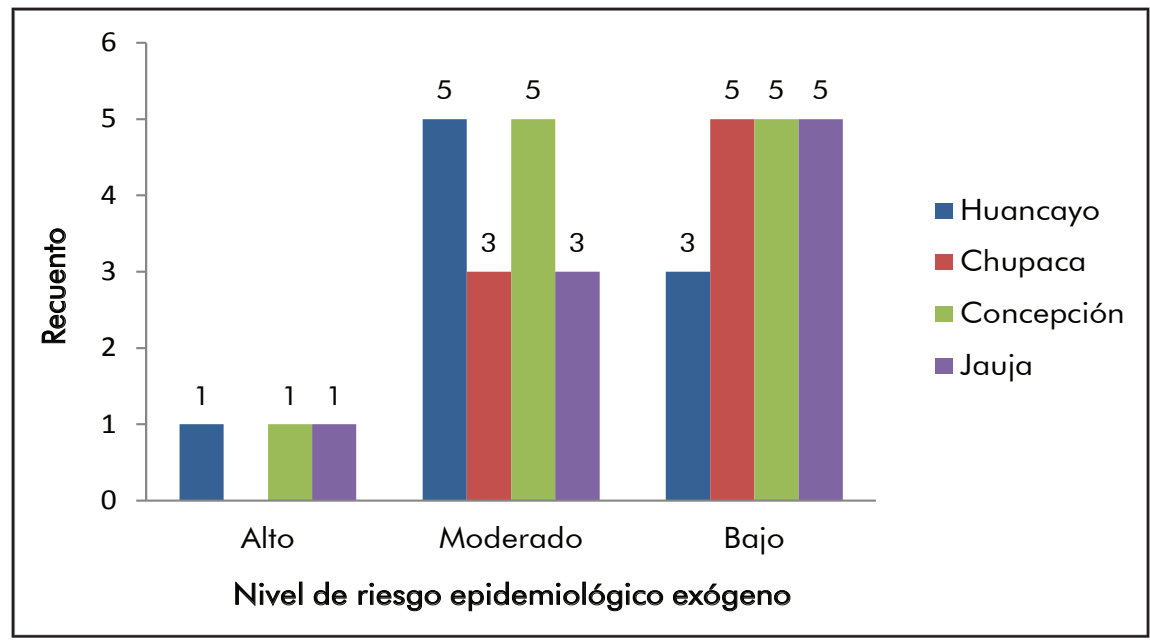

Figura $\mathrm{N}^{\circ}$ 3: Niveles de riesgo exógeno/provincia.

los factores endógenos como aquellos que dependen principalmente de las prácticas de manejo en el establo, el riesgo epidemiológico alto para la presencia de DVB y Neosporosis se presenta en 25 hatos $(67,6 \%)$, siendo mayor riesgo en la provincia de Jauja y en menor grado en las otras provincias; el riesgo epidemiológico moderado se presenta en 11 hatos $(29,7 \%)$, y el nivel de riesgo epidemiológico bajo en un solo hato $(2,7 \%)$ ubicado en la provincia de Huancayo; es decir que en las dos terceras partes de Chupaca). Los factores exógenos o externos al establecimiento pecuario, se presentan como riesgo sanitario de nivel bajo ( 18 hatos/48,6 \%) y moderado ( 16 hatos/43,3 \%) y en un nivel alto en solo 3 hatos $(8,1 \%)$, lo que nos indica que los factores exógenos no son muy importantes como riesgo epidemiológico para la presentación de DVB y Neosporosis. 
Tabla $N^{\circ}$ 4: Factores ambientales y de manejo frente al riesgo de enfermedades - Niveles de riesgo o de protección.

\begin{tabular}{|c|c|}
\hline Variable & $\begin{array}{l}\text { Interpretación sobre factor } \\
\text { de riesgo o de protección }\end{array}$ \\
\hline Tipo de crianza & $\begin{array}{l}\text { La cría solo de bovinos es un factor de protección (OR: 0,210) para } \\
\text { Neosporosis en relación a la crianza "mixta". }\end{array}$ \\
\hline $\begin{array}{l}\text { Sistema de } \\
\text { producción }\end{array}$ & $\begin{array}{l}\text { OR: 6,545; el riesgo de DVB es } 6,55 \text { veces superior en hatos de crianza } \\
\text { intensiva que en hatos semi-intensivos y extensivos. }\end{array}$ \\
\hline Tipo de servicio & $\begin{array}{l}\text { El uso de IA o mixta (IA/MN) (OR: } 7,895) \text { es factor de riesgo para DVB } \\
\text { con relación a los hatos que sólo practican la } M N \text {. }\end{array}$ \\
\hline $\begin{array}{l}\text { Tipo de higiene, } \\
\text { manejo sanitario } \\
\text { y de personal }\end{array}$ & $\begin{array}{l}\text { La higiene (OR: } 17,5) \text {, manejo sanitario (OR: } 7,5) \text { y manejo de personal } \\
\text { (OR: 12,75) inadecuados, son factores de riesgo para casos de } \\
\text { Neosporosis en el hato }\end{array}$ \\
\hline $\begin{array}{l}\text { Presencia de } \\
\text { ratas }\end{array}$ & $\begin{array}{l}\text { La presencia permanente y en grandes cantidades de ratas en el hato } \\
\text { es un factor de riesgo para DVB (OR: } 5,714) \text { y para Neosporosis (OR: } \\
\text { 18,417) en comparación con hatos donde la presencia de ratas es } \\
\text { ocasional. }\end{array}$ \\
\hline
\end{tabular}

\section{DISCUSIÓN}

Los sistemas productivos prevalentes en los hatos evaluados son de tipo semi intensivo e intensivo por la tendencia de incrementar y mejorar sus niveles productivos; la crianza de bovinos de leche con otras especies como los ovinos es característico de muchos sistemas productivos en la Sierra (9). La presencia mayoritaria de ganado Brown Swiss, y luego de Holstein seguido de ganado cruzado y criollo, es consistente con los datos del último censo agropecuario, que reporta para todo el Valle del Mantaro $26,4 \%$ de ganado de raza Brown Swiss y 121,6 \% para el ganado Holstein (7).

El hecho de que la mayoría de hatos fueron de tipo abierto y semi abierto, es indicativo de una importante práctica de movilidad de animales (compra, venta, eliminación, participación en ferias ganaderas o préstamo de animales), y el que la adquisición de los reemplazos de otros hatos, sin un plan de crianza establecido, en la mayoría de hatos evaluados, constituyen factores de vulnerabilidad para contraer determinadas enfermedades (10).

Existe una tendencia de creciente desarrollo de la industria láctea en el Valle del Mantaro, corroborado con estadísticas del Sector Agricultura, que indicaba para el año 2005 una producción de leche en el valle del Mantaro de 25 mil litros diarios, con un promedio de 8 litros por vaca/día, siendo actualmente la producción de 75 mil litros diarios de leche, con un promedio de obtención por vaca de 13 litros/vaca/día. Actualmente existe gran demanda para la leche fresca, por la presencia de diferentes empresas acopiadoras (Gloria, Nestlé, Concelac, La Serranita, La Victoria, etc,) (11).
Como la mayor parte de los hatos evaluados poseen instalaciones y prácticas de higiene poco adecuadas o inadecuadas, no se alcanza una producción eficiente, tal como se esperaría acorde a las expectativas y condiciones de crianza; se debe de proveer al ganado de instalaciones adecuadas que le brinden el bienestar necesario que garantice su confort y estado de salud (14); los ganaderos en general no valoran ni priorizan este aspecto y desconocen que una buena instalación facilita el manejo y mejora el rendimiento, por lo que las vacas bien manejadas suelen tener mejores producciones.

La mayor parte de los establos están muy cerca o en el mismo centro poblado por el acelerado crecimiento de los poblados, lo que origina una disminución de las áreas dedicadas a las crianzas; esto indirectamente tiende a una mayor "intensificación" de los modelos de crianza, pero acarrea problemas de salud y salubridad (12). Esto explica también el uso de agua potable de la red pública como fuente de agua de bebida para sus animales, mientras que en los establos más alejados de las zonas urbanas se emplean los puquiales, acequias de regadío o dos o más fuentes, de acuerdo a la disponibilidad y asequibilidad. La presencia de ratas (ocasional o permanente) en la totalidad de establecimientos, y una presencia importante de otras especies (aves silvestres, venados, zorros, etc.), pueden constituir un factor de riesgo importante para la introducción de muchas enfermedades, entre ellas DVB y Neosporosis (22).

La creciente implementación del ordeño mecánico en la ganadería del Valle del Mantaro debería asociarse con mejores prácticas en el ordeño, aunque esto no siempre ocurre así; se ha observado en la mayoría de los casos que esta labor se realiza con muchas deficiencias, lo que incrementa la posibilidad de 
trastornos y enfermedades en la ubre, disminución del estado de salud general del animal y presentación de otras enfermedades.

Debido a que la mayoría de productores suministra alimentación complementaria/suplementaria a su ganado, esta práctica demanda la existencia de lugares de almacenamiento o de suministro del mismo, adonde son atraídos roedores y otros animales que son potenciales presas para los hospederos definitivos de $N$. caninum, lo que estaría ocasionando que en estos lugares haya mayor contaminación con las heces de los hospederos definitivos, aumentando así el riesgo de infección postnatal con Neosporosis (12). La literatura reporta que el uso de alimentos balanceados y ensilado en la alimentación animal es un factor de riesgo para la Neosporosis (13).

Las prácticas de manejo sanitario constituyen factores de riesgo importantes para la presentación de numerosas enfermedades en el hato, tales como DVB y Neosporosis. La eliminación de restos y fluidos placentarios, luego de un parto normal o distócico, resulta importante como medida de profilaxis para evitar diseminar los patógenos en el ambiente, o que los perros u otros cánidos susceptibles puedan ingerirlas, cerrando el ciclo vital de N. caninum (10); el hecho de que la mayoría de hatos evaluados declararon realizar malas o inadecuadas prácticas de eliminación de estos restos, demuestra la ignorancia o desidia de los productores para no realizar prácticas adecuadas.

El manejo de información a través de la implementación de los registros y su utilización sirve de base para el análisis de los resultados técnico-económicos de los hatos, a la par que proporciona un medio de control y mejora de la eficiencia administrativa. El uso inadecuado de los registros está asociado con hatos donde existen problemas sanitarios en sus animales (16).

El personal del establo suele especializarse en más de una función (ternerero, ordeñador, pastor, limpieza) para cumplir con las expectativas del propietario o administrador. Una política de incentivos al personal puede ser favorable para obtener buenos resultados en la producción y una mayor identificación del empleado con la problemática sanitaria del ganado, pues el personal necesita ser sensibilizado sobre los programas de prevención y control de enfermedades que se siguen en el hato. Existe cierto grado de desconocimiento, entre los propietarios y administradores, sobre este aspecto y sobre el cual hay que actuar como estrategia de buenas prácticas.

En Lima se atribuye a los problemas reproductivos un $52,7 \%$ las causas de descarte (17), donde la tasa de reemplazos es más alta y los animales están más expuestos a la presión de selección y a mayor cantidad de problemas reproductivos en la medida que se incrementan los niveles de producción (18); sin embargo en el Valle del Mantaro, donde no se alcanzan los altos niveles productivos individuales de otras cuencas lecheras importantes del país, la edad es el factor más importante para la saca de ganado.

En la tabla 2 se consigna un valor de número de servicios/preñez promedio de 2,14, valor similar al reportado por otros investigadores en otras partes del país (14), aunque se halla por encima del óptimo recomendado (menos de 1,5 a 1,7 servicios/preñez), considerándose como vaca problema cuando es 2,5 (15).

En la tabla 3 se aprecia que el promedio de perros/ establo es 3, aunque se ha determinado que este factor no es determinante para la presencia de Neosporosis y DVB.

El ganado bovino que ha tenido contacto con heces de los perros puede infectarse de varias enfermedades entre ellas la Neosporosis; cuando un perro se come la placenta o los fetos y luego deja sus heces en fuentes hídricas o pasturas, se corre el riesgo de que transmitan el parásito al ganado (10).

El origen de las vacas repetidoras es multicausal y multifactorial, y el síndrome de la vaca repetidora (SVR) es considerado, después del anestro posparto, como el problema reproductivo más importante en el ganado lechero y ambos son las principales causas de una baja eficiencia reproductiva (19). Este problema se ha detectado en un buen número de hatos, por lo general en los de más alta producción y con ganado mejorado, lo cual es concordante con reportes que indican que la mejora en la producción de leche se deriva en un incremento de los problemas reproductivos (18). En un estudio realizado en Minas Gerais, Brasil, al evaluar la relación entre las anormalidades reproductivas y la seropositividad a $N$. caninum en vacas lecheras, se encontraron varias anormalidades reproductivas asociadas con esta enfermedad, como repetición de servicios, abortos espontáneos frecuentes y anestro temporal (20).

Los abortos y casos de mortinatos suelen ser causas comunes de retención placentaria (21). Se ha encontrado una incidencia alta de estos casos en la mayor parte de hatos evaluados, aunque no todos estos problemas pueden atribuirse a problemas peripartales; hay que considerar causas como la presencia de ciertas enfermedades abortígenas (DVB y Neosporosis); se sabe que el mayor impacto económico de la infección con el VDVB es el ocasionado por los trastornos reproductivos (22). DVB y Neosporosis pueden causar abortos y nacimientos anómalos, lo cual refleja la importancia de estos problemas; por 
observaciones propias y las reportadas por los propios ganaderos encuestados, una de las malformaciones congénitas más frecuentes fue la artrogriposis congénita, caracterizada por la rigidez permanente de una o varias articulaciones en flexión o extensión (23, 24).

En concordancia con la tabla 4 se definen los factores de riesgo o de protección para la presentación de casos de DVB y Neosporosis, encontrando que el tipo de sistema de producción intensivo o semi intensivo, el uso de la IA ○ IA/MN (inseminación artificial alternada con monta natural), los tipos de higiene, manejo sanitario y del personal inadecuados, así como la presencia constante y masiva de ratas en el establecimiento, han demostrado ser factores de riesgo importantes para la presentación de estas enfermedades, existiendo asociación positiva entre altas prevalencias de DVB con la presencia de vacas repetidoras y de casos de abortos y nacimientos anómalos en el hato, lo cual no ocurre para el caso de Neosporosis. La cría exclusiva de bovinos en el establecimiento resultó ser factor de protección para Neosporosis frente a la crianza "mixta" de bovinos con otras especies.

Las conclusiones son: la mayor parte de hatos evaluados emplean sistemas de producción semi intensivo con ganado mejorado (Brown Swiss y Holstein), son de tipo abierto o semi abierto, con uso importante de ordeño mecánico y dos veces/día, alimentación al pastoreo y alimentación complementaria en estabulación; de tipo mixto, 78,4 \% usa IA exclusivamente o alternando con MN (promedio de servicios/preñez 2,14); la mayor parte de las variables evaluadas están categorizadas como poco adecuados o inadecuados (instalaciones, uso de registros, manejo sanitario y reproductivo, de personal, sistemas de higiene y limpieza, manejo reproductivo); con 3 perros/establo, en todos hay presencia de ratas y se usa agua potable (red pública) y otra fuente; $64,8 \%$ de hatos reportaron de 1 a más de tres casos de vacas repetidoras, $67,6 \%$ de uno a más de tres casos de retención placentaria y metritis en el último año; 40,5 \% reportó solo casos de aborto y $37,9 \%$ abortos y nacimientos anómalos durante los últimos tres años; el riesgo epidemiológico endógeno (alto y moderado) está presente en las cuatro provincias asociado al mayor número de casos de DVB y Neosporosis siendo menos trascendente los factores de tipo exógeno para la presentación de estas enfermedades reproductivas; son factores de riesgo para DVB: sistema de producción de tipo intensivo, la IA, la presencia constante y masiva de ratas, existiendo asociación positiva entre altas prevalencias de DVB y presencia de vacas repetidoras y casos de abortos y nacimientos anómalos; son factores de riesgo para Neosporosis: presencia masiva y constante de ratas, manejo sanitario y del personal inadecuados, comportándose como factor de protección la crianza mixta con otras especies domésticas.

\section{REFERENCIAS BIBLIOGRÁFICAS}

1. Alfaro C. Salud y productividad en sistemas de producción ganaderos. FONAIAP DIVULGA. 2000; (66): p. 48-52.

2. Contreras NG, Stahl K, Arana DC, Rivera GH. Anticuerpos contra el virus de la diarrea viral bovina en muestras de leche de bovinos del Valle del Mantaro (Jauja, Concepción y Huancayo). Rev Inv Vet Perú. 2000; 11 (1): p. 58-65.

3. Ståhl K, Rivera H, Vagsholm I, Moreno LJ. Bulk milk testing for antibody seroprevalences to BVDV and BHV- 1 in a rural region of Peru. Prev Vet Med. 2002; 56(3): p. 193-202.

4. Puray CN, Casas AE, Falcón PN, Casas VG. Prevalencia de N. caninum en bovinos en empresa ganadera de la sierra central del Perú. Rev Inv Vet. 2006; 17(2): p. 189-194.

5. Granados SJ. Frecuencia de Neospora caninum en bovinos lecheros de 4 distritos del Valle del Mantaro (Junín). [Tesis de pregrado]. Lima: Universidad Nacional Mayor de San Marcos, Facultad de Medicina Veterinaria ; 2012.

6. Wayne D. Bioestadística: base para el análisis de las ciencias de la salud. 5th ed. México : Ed. Limusa; 1996.

7. Instituto Nacional de Estadística e Informática. [Online].; 2012 [cited 2015 agosto 20]. Available from:

http://proyectos.inei.gob.pe/web/Documentos Publicos/ResultadosFinalesIVCENAGRO.pdf.

8. Pérez S. monografias.com. [Online].; 1993 [cited 2015 julio 15]. Available from: http:// www.monografias.com/trabajos93/validacioncuestionario-medicion-satisfaccion-clientes-dci/ validacion-cuestionario-medicion-satisfaccionclientes-dci.shtml.

9. Núñez E, Yaranga R, Zubieta R. Antecedentes generales de la ganadería en el valle del Mantaro. In Instituto Geofísico del Perú. Manejo de riesgos de desastres ante eventos meteorológicos extremos en el valle del Mantaro. Lima: IGP; 2012. p. 167 179.

10. Delgado A, Sandoval R, Montenegro M. Actualidad Ganadera. [Online].; 2015 [cited 2015 agosto 18. Available from:

http://www.actualidadganadera.com/articulos/ Neosporosis-bovina-un-problema-latente-de-laganaderia.html.

11. Castillo G. Valle del Mantaro es cuenca lechera. Correo. 2014 septiembre.

12. Barling KS, Sherman M, Peterson M, Thompson J, McNeill J, et al. Spatial associations among density cattle, abundance wild canids, and seroprevalence $N$. caninum in beef calves. J Am Vet Med Ass. 2000: p. 1361-1365.

13. Fort M. Neospora caninum: estudio seroepidemiológico en bovinos de la provincia de 
La Pampa. Informe técnico. La Pampa: Instituto Nacional de Tecnología Agropecuaria; 2011.

14. Ortíz DA, Camacho JS, Echevarría LC. Parámetros reproductivos del ganado vacuno en la cuenca lechera de Lima. Rev. Investig. Vet. 2009; 20(2).

15. Ortiz DF. Índices reproductivos del ganado vacuno en la cuenca lechera de Lima. Tesis de pregrado. Lima: Universidad Nacional Mayor de San Marcos, Facultad de Medicina Veterinaria; 2006.

16. Malaver M, Pezo S, Blanco M. Manual práctico de ganadería: alimentación animal, sanidad animal, mejoramiento Lima: ITDG; 2003.

17. Orrego JA, Delgado AC, Echevarría LC. Vida productiva y principales causas de descarte de vacas Holstein en la cuenca de Lima. Rev. Inv. Vet. 2003; 14(1).

18. Hernández CJ, Morales RJ. Falla en la concepción en el ganado lechero: Evaluación de terapias hormonales. Vet Méx. 2001; 32: p. 279-287.

19. Palomares-Naveda R. Diagnóstico de la diarrea viral bovina para la mejora. In González C, Madrid N, Soto E. Desarrollo Sostenible de Ganadería Doble Propósito. Zuliana: Fundación GIRARZ; 2008. p. 649-661.

20. Bruhn FR, Daher DO, Lopes E, Barbieri JM, da Rocha CM, et al. Factors associated with seroprevalence of Neospora caninum in dairy cattle in southeastern Brazil. Trop An Health and Product. 2013; 45(5): p. 1093-1098.

21. Clarence M. Manual Merk de Veterinaria. 5th ed. Barcelona: Merk; 2000.

22. Lertora WJ. Diarrea viral bovina: actualización. Rev. Vet. Fac. Cs Vet. 2003; 14(1): p. 42-49.

23. Magnano G, Gonzales E. Artrogriposis congénita en terneros: descripción de 2 brotes en rodeos de cría. RECVET. 2007; 2(12): p. 1-7.

24. Anderson ML, Barr BC. Protozoal causes of reproductive failure in domestic ruminants. Vet Clin North Am: Food An Pract. 1994; 10: p. 439461. 